\title{
The challenges of launching, rating and regulating funds of hedge funds
}

\author{
Joaquín López Pascual* and Raul Daniel Cuellar \\ *University King Juan Carlos, Madrid, Spain. \\ Tel: +34 914887 784,Fax: +34 915941 366, E-mail: joaquin.lopez@urjc.es; \\ rd.cuellar@alumnos.urjc.es
}

Received (in revised form): 14th August, 2008

Joaquín López Pascual is Bank Management Chair of Faculty of Law and Social Science, University King Juan Carlos Madrid.

Raul Daniel Cuellar is a researcher at the Bank Management Chair of Faculty of Law and Social Science, University King Juan Carlos Madrid.

\section{Practical applications}

Funds of hedge funds are emerging as a preferred route of access by investors allocating to hedge funds. We consider the challenges facing these entrepreneurial ventures in accessing investments when seed investment is insufficient and the criteria that investors may use during their assessment of investment risk. We analyse the role of rating agencies in rating funds of hedge funds and the applicability and implications of their rating methodology. Moreover, we consider the impact that regulation of hedge funds could have on their industrial structure.

\section{Abstract}

Funds of hedge funds (FOF) are the preferred channel to access hedge funds by investors. FOF add value through selecting the best managers from a large universe, performing due diligence, and monitoring investments and risk. Initial funding of an FOF is a difficult task. Despite holding positions in well-established funds, new FOF are not able to use this fact to gain investments because the composition of the portfolio should not be disclosed. We analyse some of the difficulties of funding start-up FOF, the rating used by rating agencies,

Journal of Derivatives \& Hedge Funds, Vol. 13 No. 3, 2007, pp. 247-262 (C) 2007 Palgrave Macmillan Ltd $1753-9641 \$ 30.00$ and the possible negative effects of regulation by the G8.

Journal of Derivatives \& Hedge Funds (2007) 13, 247-262. doi:10.1057/palgrave.jdhf.1850076
Keywords: hedge funds; alternative investments; funds of hedge funds; rating; risk analysis

\section{INTRODUCTION}

Funds of hedge funds (FOF) are becoming the preferred way to access the world of hedge funds, not only by institutional investors but also increasingly by retail investors. Because of the regulatory frame, in many countries such as Spain they will be the main investment channel for alternative investments. Low initial investment, shorter lock-up time, low volatility, and double-digit returns contribute to an FOF becoming the favourite investment vehicle for investors, who also recognise the advantages of 
the due diligence, increased transparency, and monitoring functions assumed by FOF managers.

For their services, FOF managers charge an extra fee on top of the fees levied by the underlying constituent funds for management of the assets, as well as for the performance of each underlying fund. FOF managers do not have an easy task, however. They assume the responsibility for investors of selecting about 10-30 underlying funds, considered the winners from a universe of more than 9,000 existing funds, then monitoring and rebalancing their portfolio, as well as gaining exposure to sectors and assets with the best performance outlook in a way that results in a solidly diversified portfolio. Managers of FOF perform top-down analysis, assessing where there is risk of low returns, where to take risk for higher returns, and macrotrends or sector rotators. They also perform bottom-up analysis, assessing the attractiveness of different sectors or the underlying fund manager's skills. Despite the disciplined and scientific approach to selection, investing, monitoring, and rebalancing, however, FOF tend to underperform single manager hedge funds.

Hedge funds tackle opportunities with different strategies and with different instruments. Returns in hedge funds are notoriously asymmetrically distributed, presenting high kurtosis and negative skewness, typically the result of trading in derivatives and illiquid securities in different markets. Managers of FOF have to continuously maintain a clear overview of the risk at the single hedge fund level and at the aggregated portfolio level in order to rebalance their portfolio, reducing undesired exposures and gaining exposure to risks providing superior returns.
The relevance of FOF for investors cannot be understated because they relieve investors from the tasks of fundamental importance in performing a professional investment process. In this context, FOF should be considered as new intermediators. The value added for investors does not come free of charge and should not be either, because FOF charge fees on top of the fees already charged by the underlying fund and there is the possibility that despite the fact that an FOF does not make money, the FOF is still allowed to charge to its investors a performance fee based on the performing underlying funds.

Because investors in hedge funds want to gain exposure to the best returns while minimising their risk, FOF managers select among the best performing and least risky hedge funds for their portfolio constituents or they blend risky with less risky managers in a way that risk is mitigated by the weight of less risky ones. At all times, FOF managers maintain a clear balance of risk concentration levels, which is a critical aspect in hedge fund management. To do so, FOF managers maintain regular contact with the underlying hedge fund managers, monitoring and analysing the position report from the different underlying funds. The composition and the level of exposure and rebalancing strategy are key factors of success in FOF. In many cases, FOF allocate to managers with many years of experience and a long track record of success. FOF managers are, however, unable to disclose their positions to their investors.

This latter fact builds a considerable obstacle to emerging FOF managers, who may find difficulties raising funds because investors demand certain conditions considered as assurances that the FOF will not go out of business. Such conditions come in the form of returns, volatility, assets under management 
(AUM), track record of the fund, track record of the FOF manager, investment process, due diligence process, and liquidity gates, among other factors. The importance of the track record of the FOF is in many cases very overstated in the assessment of FOF. Since FOF invest in other funds, it could be asserted as unfair to discriminate an FOF based solely on the track record of the fund, where the track record of the underlying fund should bear the most relevance. As the composition of the FOF cannot be disclosed, however, emerging FOF find their way to investment seriously undermined.

In the case of rating of FOF by rating agencies, despite the fact that the most relevant criteria should be disciplined and institutional screening, selecting, and monitoring processes, rating agencies include in their assessment performance criteria and risk measurements that are hardly applicable to FOF and hedge funds, such as the Sharpe index.

Following concerns about instability effects, which hedge fund risks could possibly induce to capital markets and the entire financial system, the G8 are considering re-evaluating the role of rating agencies in assessing overall risk management practises by hedge funds and FOF, giving more legal relevance to the rating of hedge funds. Regulation of such an entrepreneurial environment can induce negative effects by increasing barriers to enter into the industry, creating an oligopolistic environment with resulting negative effects for investors, and by repelling emerging talents from building their own investment organisations.

From an entrepreneurial point of view, we analyse some of the problems that FOF experience pertaining to launching of the fund and the potential impact of rating and regulation.
The paper is divided into three sections. The first section analyses the problems related to initial funding of a start-up FOF as a new entrepreneurial venture in the financial industry. In the second part, we assess the possible difficulties in rating FOF by rating agencies. This is of particular importance in view of the role that future regulation intends to give to the rating of hedge funds and the impact that such a rating can have on the entrepreneurial environment in the financial industry. In the third part, we reflect about the possible effects of regulation in the industry and the consequences for FOF and new ventures in the sector, as well as the possible consequences for investors. We conclude this paper by assessing the impact of regulation and possible compulsory rating on the entrepreneurial finance and FOF sector.

\section{FOF FUNDING}

\section{Overcoming rules of investment for a single manager hedge fund}

From an investor's perspective, when considering hedge funds, it is important to allocate to an investment vehicle that exhibits a consistent pattern of returns, low correlation with the markets and low volatility, as well as a demonstrated level of professional ability of the management. Different strategies yield not only different risk exposures but also expose the investment to common risks across the hedge fund portfolio. In this respect, it is important to conceptualise that FOF have as their principal task not only the selection of the best performers and less risky funds in their portfolio but also the diversification of their portfolio.

A nondiversified hedge fund portfolio always brings the latent risk of high risk concentration 
and financial distress. A well-diversified hedge fund portfolio is only achievable by increasing the number of underlying funds across different strategies with the subsequent negative effect that fees bring on the wealth transfer process between manager and investor. As research has proven, ${ }^{1}$ the results for investors of this fee structure come in the form of fee multiplication. This diversification and its negative fee effect are at the source of FOF underperformance relative to single manager hedge funds. Moreover, some investment organisations create their own products with a basket of underlying single manager hedge funds and FOF managers, building a triple fee structure or a fund of FOF with the consequent attrition effect on performance but with a positive effect on diversification. On the other hand, as it is well known, increasing the number of funds in the portfolio can also eventually have the positive effect of reducing significantly the negative skewness present in an FOF because, as research has established, when adding positively skewed funds to a group of negatively skewed funds, the negatively skewed funds are relatively diluted.

Further, recent empirical research ${ }^{2}$ has established the negative impact of low lock-up times on the performance of hedge funds. Given the fact that many strategies allocate to underlying securities with low liquidity, matching allocation and investment duration by establishing correct redemption policies constitutes a particular challenge not only for hedge fund managers but particularly for FOF managers, who have to combine the redemption policies of different underlying hedge funds.

Low correlation with markets is also a very important attribute when selecting an FOF. Empirical research ${ }^{3}$ has robustly established the virtues of including alternative assets in the allocation process, given the low and even negative correlations with traditional asset classes. Many FOF managers eager to justify their double fee structure could, however, shift their objective and allocate to underlying strategies with excessive risk and high expected returns, even at the cost of increasing their correlation with the markets and therefore sacrificing their primary mission to act as a portfolio diversifier.

Institutional investors have traditionally used a disciplined investment process to allocate to hedge funds. Recently, rating agencies are entering the world of alternative investments by rating hedge funds and FOF using a similar screening process as traditionally used by institutional investors. This screening process is fundamental for investors.

\section{Portfolio of hedge funds risk measurement}

Investment in hedge funds presenting significant asymmetries in their return distributions suggests that a mean-variance approach is not appropriate to achieve portfolio optimisation. Agarwal and Naik, ${ }^{4}$ based on the research by Fung and Hsieh, ${ }^{5,6}$ established that a number of nondirectional hedge fund trading strategies present return patterns similar to option-based strategies. It can therefore be affirmed that option-based trading strategies are an optimal proxy to assess hedge fund returns in some cases. Despite this well-proven fact, rating agencies as well as institutional investors consider ratios applicable for normal and symmetrical distribution as key factors in assessing the risk and performance of hedge funds and $\mathrm{FOF}^{7}$ despite the very well-established fact that such measures do not capture hedge funds risk in its 
entire dimension. In this sense, we have to consider the limitations offered by the Sharpe index, where different research ${ }^{8-12}$ has established that the use of the Sharpe index in relation to risk measurement and portfolio construction in hedge funds provides investors with misleading risk information.

In this respect, the performance assessment of FOF is not such a straightforward question, given the fact that it is difficult to establish a benchmark and also because hedge fund indices exhibit a relevant level of tracking error.

Moreover, many hedge funds, trading in illiquid securities, present smoothing appraisals similar to real estate valuation indices and therefore, nondedicated indices are fully inappropriate to benchmark them. When assessing returns of a fund, the manager of the FOF has to have under relative consideration the monthly returns of the fund. This is particularly so because as Brooks and $\mathrm{Kat}^{13}$ and further research ${ }^{14}$ have demonstrated, monthly returns in hedge funds exhibit a high degree of autocorrelation. The reason for this autocorrelation can be found in the fact that many hedge funds invest in illiquid securities that are difficult to mark to market and when confronted with a frequent NAV calculation, the fund manager uses a conservative approach to asset valuation, which creates an artificial lag and smoothing of returns and volatility estimates become downward biased.

Recently, one of the most reliable sources of performance analysis is the use of peer groupbased performance, which seems to be the most appropriate form of performance assessment and has been gaining popularity among investment managers and consultants.

Hedge funds gain exposure to their own set of specific risks through poor liquidity, use of leverage, high turnover, frequent use of derivatives instruments, just to mention a few. Risk measurement in traditional investment vehicles or asset classes is in fact a very straightforward exercise when compared with risk measurement in hedge funds. Assessing the risk management of an FOF can become complex and difficult because in order to successfully manage risk, FOF managers have to be able to clearly understand the risks of each underlying strategy and aggregate them at the FOF level in line with the hedge fund portfolio risk policies in a meaningful way. In this context, FOF's operational risk management is a fundamental criterion in the screening, selecting, and rating of such vehicles.

One of the main challenges for investors and FOF managers is the poor transparency of hedge funds, which is the main source of many risk modelling misspecifications. Hedge funds dynamic investment strategies are a challenge in risk measurement for FOF managers and rating agencies in their assessments. Given these dynamic trading strategies, it is not an easy task for FOF managers to reduce risk measurement error to near zero. Identifying risk in a dynamic investment environment across different investment styles using different asset classes in different markets requires high-frequency assessments, superior information, and great accuracy that come as a result of high transparency.

FOF establish privileged relationships with hedge fund managers obtaining a higher degree of transparency that is otherwise not obtainable by regular single manager hedge fund investors but also this privileged relationship extends to such a level that FOF are able to allocate investments in funds that are closed for other investors. This level of transparent and close relationship, however, is not extensively passed 
on to the FOF investor, with the important exception where the FOF is able to allocate to a fund that is otherwise closed to investors. Nevertheless, there are FOF managers who on finding some underlying hedge fund hard closed to new investments, circumvent this allocation obstacle by implementing a system of secondand third-tier funds in their selection approach, which allows them to find an open fund with attributes similar to the one that is hard closed. This approach has been well illustrated in research by Gregoriou and $\mathrm{Zhu}^{15}$ using data development analysis (DEA). FOF managers consider that disclosing positions and high transparency in the underlying vehicles could negatively affect the relationship between investor and the fund by enabling the opportunity for disintermediation. In this context, a third-party risk assessment is one of the possible solutions implemented by the industry with success. An exception to this common practice is made by FOF managing 30 or more underlying managers, because they usually disclose their top 5-10 positions.

Quantitative assessment by investors of FOF has the objective to establish the persistence and solidity of the risk-adjusted returns of the investment organisation over a certain timeframe. This is a complex task not only given the asymmetry of the returns and the diversity of risk exposures but also because it requires having an assessment tool that takes into account the multidimensionality of the assessment. In this sense, seminal work by Gregoriou and $\mathrm{Zhu}^{15}$ using DEA in assessing performance and ranking of hedge funds as well as FOF construction represents a significant contribution to allocators. For this purpose, however, most investors and in particular rating agencies using traditional methods based on normal return distribution, particularly mean and variance, consider data from the last three years of trading of the vehicle. In general, this is in disagreement with the investors' selection process because they instead assess the level of risk-adjusted returns (alpha) generated by an FOF. Alpha is an important criterion in hedge fund selection. Recent research ${ }^{16}$ has demonstrated that funds exhibiting high levels of alpha see significant investments independent of their returns, while low-alpha generating funds see investment flows only based on their returns. The same research, however, establishes that funds attracting significant levels of capital tend to experience a reduction in their alpha.

FOF, despite allocating to funds with very large consolidated track records, are not able to present specific data that will be able to produce a statistically significant analysis. In general, the industry considers that five years is a sufficiently long track record in order to trust the persistence of returns of a fund. Ineinchen, ${ }^{17}$ however, disputes the reasoning of these criteria and $\mathrm{Kat}^{18}$ considers the weight placed by investors on the manager's track record as excessive. The track record should be considered in the frame of the statistical evidence that generally shows a gradual reduction in FOF returns after a period of consolidation. The proforma portfolio of start-ups is normally not considered to be of fundamental relevance in this assessment. Instead, some investors consider AUM to be a positive factor that would mitigate the lack of track record of the FOF or even insufficient disclosure of operational risk management. This does not come as a surprise because empirical research ${ }^{17}$ has clearly established that nonsurviving FOF have significantly lower AUM than surviving funds, so that AUM is indeed a clear implied assurance to new investors 
that the fund has good chances to survive, given that a large AUM demonstrates the trust placed by investors in the management quality of the FOF. This is a particularly important point because when a large part of the initial FOF's funding comes from the manager's pre-existing business relationships, it implies a high level of trust by this investor in the demonstrated abilities exhibited by the FOF manager over the period of his employment.

To overcome these initial funding difficulties, start-up FOF are better served by having an initial investment or seed investor that is able to cover the initial costs of the organisation within a horizon of about two or three years, with particular attention given to obtaining seed funding from former employers or pre-existing business relations. With a fund that is initially well funded, with solid risk-adjusted returns, at least two years of track record, and low market correlation, FOF managers do not find serious difficulties in attracting investors. The most important aspects in an FOF, however, are namely operational risk management, due diligence, as well as monitoring and rebalancing strategies of the underlying constituent fund managers, which should also be reflected in the returns and volatility over a period of two years.

\section{RATING FOF}

\section{Rating FOF - A very complex task}

Rating FOF presents many challenges for rating agencies, which only recently have started to rate hedge funds as well as FOF on request of the fund management. Moody's has started to provide hedge funds and FOF with ratings on operational quality based on 'back office administration, regulatory compliance, risk reporting and control, legal and financial structure as well as human resources criteria'. These criteria, however, do not capture the effects of the most important aspects of FOF management. Monitoring is one of the most critical factors to success in managing an FOF but is undervalued by the rating agencies, which also undervalue the important process of rebalancing strategies and reassessment of the composition of the FOF portfolio, through eliminating some funds and including others, expanding or contracting the investment according to the situation and the strategy of the FOF manager in accordance with his overall assessment of the macro environment, switching between an aggressive and a defensive portfolio composition.

Another aspect of fundamental importance to consider in hedge fund portfolio management assessment is the monitoring of the underlying hedge funds for the possible presence of style drifting. Style drifting in an underlying hedge fund can potentially have an offsetting result in the diversification and risk exposure structure of the hedge fund portfolio. For this purpose, statistical analysis assessing the return characteristics of a hedge fund can put in evidence possible style drift by an underlying hedge fund manager. To perform such a statistical analysis, however, the FOF's managers have to take into account a sufficiently long horizon that explains its trade-off structure. The use of multi-scale correlation methods can assist portfolio managers in establishing the right time horizon for the analysis. Two significant problems in the analysis are quite frequent. The first is that the time horizon of the assessment is too short and the point of divergence (convergence) between the explaining factors and the portfolio return streams cannot be 
evaluated with a certain degree of accuracy. The second problem is that the established time horizon is too long, diluting the effects of the factors so much that the factors combination and the moment relation can hardly be visualised. When the factors and the returns converge in a time series, there is equilibrium between established or contractually agreed risk factors and the returns typical for a certain investment style. Once the observation of returns and the explanatory statistical factors in the time series start to diverge, the FOF manager is left without knowledge of the risk factors, which is normally a sign that the underlying hedge fund manager is incurring style drifting or diverting from the investment style that the parties have originally contractually agreed.

Another system used by FOF managers is the Returns-Based Style Analysis (RBSA) developed by Sharpe. ${ }^{19,20}$ Although its application has been conceived for mutual funds analysis, practitioners in the area of hedge fund investments and FOF managers have been using it with success in order to assess style drifting by hedge fund managers, identifying when style reclassification is taking place. An interesting discussion about the possible application of RBSA to hedge funds has been presented in research by Schwindler and Oehler. ${ }^{21}$ Visualising style drifting is of utmost importance for FOF managers with institutional allocations in their portfolio, given the contractual rigidity of the investment mandate and their fiduciary responsibility. In order to better assess underlying managers, the FOF manager ideally should have full position-level transparency. This is a fundamental aspect in the operational risk management of FOF, which rating agencies or assessment by investors must take into account. In general, the problem facing the use of RBSA is that the methodology demands a regression of the hedge fund's historical returns against the returns of a constructed passive portfolio used as a reference or benchmark. The construction of such a benchmark or reference portfolio is not always a very simple task because alternative investments in general are, or should be, with a very low correlation level to traditional asset classes. Moreover, the methodology can clearly distinguish only four different hedge fund clusters and therefore a fine-grained decomposition needs to be applied for the purpose of risk assessment in FOF.

\section{Negative effects of rating on including emerging talents}

FOF managers are also expected to have the ability to identify emerging talented managers with promising new funds, which logically do not fit in the style drifting statistical analysis and require a more dedicated qualitative approach and follow-up by the FOF manager. The selection of emerging talents is for any FOF with a long-term horizon of significant importance because on the one hand, their seed investments guarantee privileged allocations and relations with possible future important managers, as well as future star managers and, on the other, investing in new talents in this entrepreneurial environment means to gain access to a pool of new ideas, which represents an important factor in extending the frontiers of alternative investments. Star managers attract a significant flow of funding and soon implement a so-called soft close policy, where only fund investors can increase their allocation. Star managers presenting extraordinary returns and very low volatility given a significant flow of funding impose conditions to investors that would not otherwise 
be acceptable. They reserve a certain capacity for present investors, closing the fund to new investors. Unless there is a privileged relationship such as seeded investment in the initial phase of the fund, star managers can become very nontransparent and operational risk within the FOF allocating to such managers can become only a guessing exercise. In this context, rating agencies must have under consideration the allocation level to star managers, because it could indeed affect negatively the efficiency of the FOF's operational risk management. A qualitative analysis of the relationships with underlying hedge funds constitutes an important phase in assessing operational risk management. The possible impact of the relationship with an underlying star manager in an FOF in terms of efficiency of the rebalancing strategy should be carefully assessed. Significant attention has to be given to the side letters, extra agreements, and negotiated privileges in the contractual relationship between the FOF and the star manager or any other underlying hedge fund manager. In their ranking assessment, rating agencies should consider a range of methods including the use of the Morningstar style boxes technique, which has been serving investors in their investment decisions for a considerable time. The simplicity of the graphic representation of the style box technique should, however, be taken with caution, particularly in reference to the low transparency and the complexity of returns of the investment vehicles typically found in the alternative investment industry. Statistical ranking methodologies such as DEA that address complexities of returns should also be considered in order to assist in the assessment, taking into consideration the multiple dimensions in hedge fund assessments.

\section{Risk management and measurement in FOF and its importance in rating}

Rating agencies assessing risk management practises in FOF must go beyond parametric $\mathrm{VaR}$. The practice of investment portfolio risk budgeting in the context of hedge fund management is to align risk budgeting with a coherent risk measurement methodology in order to obtain an appropriate risk amount. There are a number of $\mathrm{VaR}$ methodologies, of which the most utilised in the hedge fund industry is certainly conditional value at risk $(\mathrm{CVaR}),{ }^{22,23}$ modified value at risk (MVaR), ${ }^{24}$ modified Sharpe index, ${ }^{25}$ and mean absolute deviation model (MAD). From the perspective of FOF risk management, a key factor to successful risk management is to include a variety of measures combining both quantitative and qualitative risk analysis.

Stress test has gained significant popularity in the sector in the process of risk measurement, assessment, and monitoring. Stress test results need to be integrated into the denominator of the risk-adjusted reward equation. Stress test in the context of FOF management should include not only variations in market moves but also assumptions of the underlying strategies, as well as the possible adverse effects on the portfolio of the liquidity premium and on-the-run and offthe-run differential credit spread sensitivities. Scenario analysis is used to model the behaviour of the investment vehicle to different market or economic environments. ${ }^{26}$ The attractivity of scenario analysis and its efficiency, however, depend on the selection of the relevant variables that can affect the setting.

FOF managers control risks by closely monitoring the variety and level of exposures to different risks by the underlying hedge funds and at the aggregated level. In hedge fund risk 
management, one of the most critical aspects is liquidity risk. Investors and rating agencies need to understand the illiquid character of the securities traded by the hedge fund in the context of its strategy and the use of this attribute in return generation. Valuing positions at midmarket when positions are large and market liquidity is critical can be very misleading. Assessing contingency strategies in distressed situations is an important part of the risk management analysis. A natural reflex of managers in distressed situations is to respond to pressures from prime brokers, liquidating the most liquid instruments in the portfolio to meet margin demands. This is normally the equivalent of a death sentence because it constrains the portfolio to the most illiquid instruments, leaving the managers in a very vulnerable position in a fast moving and volatile market. We recognise that assessing contingency measures strategically contemplated by FOF managers in such a distressed scenario is a very important aspect in operating risk management assessment.

Another embedded source of risk of FOF is related to portfolio architecture that investors or rating agencies should consider. FOF managers proceed to manager selection only after carefully reviewing the so-called strategy selectors or rotators. In order to reduce single manager risk and to achieve superior returns and optimal diversification within the same strategy, it is not unheard of for some FOF managers to include more than 100 individual managers. This construction will efficiently minimise individual manager risk at the cost of reducing single manager alpha. Empirical research, ${ }^{27}$ however, has established that diversification within the same strategy does not necessarily reduce risk because in strategies with a limited quantity of trades and very negatively skewed expectations per trade, diversification at the manager level may actually increase rather than decrease risk. Moreover, megafunds managing a large number of underlying funds offering short-term liquidity but with different underlying redemption policies are subject to duration mismatch, which can severely affect the performance. An example of this could be the mega FOF of Deutsche Bank, managing 100 different underlying managers but offering to its investors daily liquidity.

The fundamental aspects to consider are the visualisation, qualification, and quantification of risk exposure. As has been well established with the use of PCA, the FOF manager can evaluate the relevant risk factors related to the underlying constituent fund's strategy and then correlate them with the real total risk factors of the FOF portfolio. This reduces the dimensionality of a multivariate forecasting overcoming the constraints imposed by the correlation of random variables and maintaining at the same time the covariation structure in the derived samples. It is prudent to remember, however, that FOFs are never, or should never be, designed solely on the basis of PCA.

Empirical research has established that in the optimal case, FOF manage around 10-15 hedge funds in their investment portfolio ${ }^{28}$; however, it is not uncommon to find FOF managers managing significant larger quantities of underlying hedge fund managers in their different sub portfolios, and so it is easy to realise the level of complexity in different risk exposures. Strategy shifting monitoring can be a very challenging task for an FOF manager. The availability of resources, technology, and the quality of the resources available for the task of monitoring and risk assessment is a very important aspect. FOF working with high 
budgetary constraints or start-up FOF under cost-saving limitations present in this context a clear challenge to investors.

Another problem in managing a hedge fund portfolio is the possibility and importance of using parametric VaR. Although it has been considered as an inappropriate risk measurement in relation with hedge funds, given the asymmetry in their returns, recent research has proposed the use of parametric VaR with constant position information ${ }^{29}$ as a possible monitoring variable in FOF management. The proposed approach presents certain limitations for FOF managers. On the one hand, VaR normally presents a high degree of volatility and making $\mathrm{VaR}$ a principal criterion or rotator could overstate the limitations in terms of risk. On the other hand, some strategies and investment styles in hedge funds are focused on such illiquid securities that to perform parametric VaR on a continuous basis (daily or weekly) as proposed is by all means a serious challenge, because the valuation of certain securities for which there is not a continuous market means that pricing possibilities can become impossible. Moreover, the limitations of $\mathrm{VaR}$ in terms of subadditivity remain a serious obstacle, particularly when applied to an FOF because it could seriously compromise the rotation policy. Despite the limitations in quantitative risk assessment, $\mathrm{VaR}$ is considered a typical risk measurement in a large number of hedge funds and FOF. Given the fact that VaR assumes normal market circumstances and return distributions, the benefits for a hedge fund or FOF of VaR implementation can be very questionable.

For risk reporting and management, aggregating risk exposures gained by the FOF in their portfolio can be challenging, given the variety of the investment styles, the trading frequency, and difficulties of valuation of underlying instruments, which in many cases are very illiquid. Other than managing the inherent risk exposure to the specific strategy, the portfolio manager must also have a clear view of risk at the single manager level and aggregate them across the entire portfolio. The assessment is particularly difficult because the underlying fund managers do not always comply with a clear disclosure of the positions or, as mentioned earlier, the valuation of the positions can still be subject to corrections due to infrequent trading or low liquidity.

The strength of FOFs is to hold a diversified portfolio of underlying hedge funds. Many FOF, however, tackle a specific market investment focus, such as geographic areas or industrial sectors. The methodology of total risk aggregation can provide the investor or FOF manager with a clear view of their focus or subfocus over-exposures. Thus, for example, a Latin American FOF could be shifting most of its focus into Brazil, neglecting opportunities in the rest of Latin America.

\section{REGULATORY EFFECTS IN AN ENTREPRENEURIAL ENVIRONMENT}

\section{The fees as a possible distortive source of market competition}

Aware of the negative effects of the double fee structure on the process of wealth transfer between investor and fund manager, many FOF managers, particularly in the initial phase of their business establish a low fee policy. In certain cases, no management fee is charged but only a performance fee. The desired effect of a low fee is to transmit to investors the message that the 
service provided by the FOF does not come to them to a high price but rather to a more 'reasonable' one, which is lower than the cost of internalising the screening, selecting, allocating, and monitoring process by an institutional investor. In this sense, FOF managers setting low fees perceive their service as a perfect substitute of an internal department or an external consultant.

Managers consider pricing of the services of an FOF under normal elasticity criteria where low fees imply higher allocations and many FOF managers consider that the cost of their service provided to investors is structured in such a way that the more the AUM, the lower the relative operational cost, implying benefits from economies of scale. This would make sense when the professional investment process provided by FOF is the same for small or large allocations, so that there is a greater efficiency when larger allocations to FOF take place. This line of argument is, however, questionable because an FOF with large AUM must include a larger number of underlying hedge funds in the portfolio, given the fact that many strategies in hedge funds are capacity constrained and as the due diligence process is performed individually fund by fund, the costs increase with the quantity of underlying funds. As many investment strategies in hedge funds, such as investment in small caps or sector focused, are capacity constrained, FOF receiving larger allocations are forced sooner to either close the fund to new investors or increase the number of underlying hedge funds in their portfolio, with the constraint that these funds, understanding their strategic limitations and the concave character of the relation between performance and attracted investment, could hard close the fund to investors. Increasing the hedge fund portfolio presents the desired effects of diversification but, as research has proven, if not carefully correctly combined, it could increase skewness, kurtosis, and even correlation with equity markets, as well as the operational cost of the fund. The operational costs increase because more effort has to be deployed to control risk and operations at single manager levels, visiting managers, assessing risk, and lining up the profile of the portfolio at all times to result in a diversified vehicle. Moreover, FOF, consultants, and internal departments are not perfect substitute products or services because the FOF manager has, by applying a performance fee, an incentive for increasing the performance of his portfolio while the others normally do not. The fact that there is no penalising system for excessive risk taking in the FOF's fee structure results in the negative effect that FOF managers aiming to obtain or justify their performance fee are indirectly incentivated to take excessive risk.

Reducing costs in operational management due to the increase in the number of underlying funds can have very undesirable effects for the investor, while an increase in the fees to finance the rising operational cost may reduce the AUM because many investors, who were originally attracted to the fund because of the low fees, may redeem their shares, negatively impacting the size of the AUM. The effects of redemptions on the AUM due to an increase of fees will make the fund's offering less attractive to its traditional market segment and will put it at disadvantage against competitors that provide the same or similar services at a lower price.

Establishing a high fee policy in the initial phase of the fund reduces the attractivity of the FOF to investors unless the fund attributes and focus are clearly differentiable and investors perceive a clear value added in the offering. On 
the other hand, when a large quantity of FOF providing similar services charge similar fees, an FOF offering its services to lower fees could be perceived either as a low-quality service provider losing attractivity for investors or successfully attracting investors and inducing price pressure on the rest of the FOF market. The possible outcome of such a scenario will depend on different differentiating factors such as the track record of the FOF manager and his team, sector or area focus, and the rating and other variables that are considered relevant for investors in building the perception of quality. Initial pricing of the FOF is a cornerstone in market positioning of the FOF in the target market segment particularly in the initial phase of the lifecycle of the fund.

In this context, the pricing strategy and market segmentation for FOF is very difficult indeed because not many FOF close because of operational risk problems or problems related to the quality of their services, making investors very aware of the importance of product differentiation. Research ${ }^{17}$ has rather established that the main reason for FOF closure is high exposure to non-equity risk and low AUM that limits the access to fresh investors. Contrary to the single manager hedge funds sector, where continuous blow-ups have created in investors a higher level of awareness about the embedded risks of many hedge fund strategies, the process of selecting a single manager hedge fund is not as sensitive to the fees as it is in the case of an FOF. The importance of fees in the survival of FOF, however, is not of significance relevance. ${ }^{30}$ In the case of FOF, the offering attributes have become so standardised that a reference price in investors' perceptions has been created and the services offered by FOF have been converted into a very homogenous service with a single price of reference.

\section{Externalities and possible regulatory impact in the industry}

Another aspect to take into account in the offering of FOF is the network externalities of FOF. The demonstrated elasticity of the price and the generally similar professional backgrounds of the vast majority of FOF managers offering a service with little dissimilarities have created a strong price of reference for investors. With more investors using FOF as a channel for their investments in hedge funds, the greater is its attractivity, because investors perceive that the channel offers a level of assurances that are not found at the single manager hedge fund level or the attributes of the extended product offer an important level of assurances or a quality of access that are not otherwise obtainable by another investment vehicle. The quality of access is an extended product attribute based on the ability of an FOF to invest in funds that are closed to new investors or to access important single manager funds using the advantages of an investment pool by participating with less than the minimum required investment by the single manager hedge fund. The more single manager hedge funds there are in the market, however, the greater is the utility of FOF for investors. The utility also increases the more single manager funds go out of business because investors perceive that FOF are able to significantly reduce the risk exposure to such extreme events. On the other hand, FOF induce pressure on fees of underlying hedge funds and as there are more failures of single manager hedge funds than of FOF, investors will rather allocate their investments to FOF than to single manager hedge funds, a fact that is confirmed by the significant rate of growth of FOF. 
The growing buying power of FOF due to high allocations in the underlying funds is indeed good news for investors that could see the fees of the underlying funds reduced. These high allocations in the underlying funds have their own risk because the balance of the allocation among the constituent funds must be maintained in such a way as to not overexpose the portfolio to any single manager or any single strategy. Nevertheless, in the long run in a market with a large number of FOF providing similar services, the perception among investors will probably grow that their offering has a homogenous character. In this context, consumer preferences tend to opt for those brands that are the strongest, which in the financial industry translates into large AUM and important branding and marketing expenses. A possible outcome of this scenario in the industrial landscape would be rather one of consolidation of the sector and higher fees due to a shift in industry structure to oligopolistic-like features with higher barriers to enter and therefore higher fees. Warnings by the G8 about the potential destabilising effects of hedge funds in capital markets have the effect of increasing investors' awareness about latent risks and raise the demand for FOF as professional investment organisations with a disciplined institutionalised screening, selection, and monitoring investment process.

The concerns expressed by the G8 and measures oriented to regulation of hedge funds can have for investors the undesired effect of inducing distortions in the industry structure, creating the environment and conditions that reduce competition and generate oligopolic-like structures that will give possible place to collusions, anti-competitive behaviour, and price fixing, as has been the case in other industries.
Another possible effect could be that the efficiency of hedge funds will be significantly reduced through high regulation because the cost of compliance to regulations will probably act as barriers to enter the industry and will possibly impair in many ways the ability to seize opportunities offered by market inefficiencies and the ability to perform and deploy dynamic fast-responding investment strategies to rapid market changes.

\section{CONCLUSIONS}

Recent implosions of important hedge funds have increased pressure on governments of the G8 to take measures to control the investment activities of hedge funds. In the case of a financial distress situation, excessive leverage, large positions in sub-prime markets, illiquid instruments, and low liquidity coefficients are considered to have a potentially devastating effect on a significant part of the financial system. In this context, recent hedge fund crises have demonstrated the fundamental importance of monitoring risk concentrations and operation management. In the frame of FOF, underlying hedge fund strategies, despite their fundamental differences, can still share a fair amount of exposure to the same risks, generating an undesired risk concentration effect. Assessing operational risk management is a critical aspect in rating FOF managers. The operational risk management, portfolio construction, and rebalancing strategies are interconnected factors with a significant impact on the overall risk assessment of the investment vehicle.

In this general frame, launching and initial funding of FOF presents challenges that are only to be overcome by sufficient initial funding and/ or significant transparency of the underlying 
positions. Funding from former business relations to the management team is considered important in demonstrating the abilities of the FOF management. High degrees of transparency in an FOF can lead to frictions in the relations between the investors and the fund. Selecting the underlying managers can present its own set of risks, which is very difficult to assess ex ante. Start-up talented managers and the presence of star managers in the hedge fund portfolio present difficulties in rating operational risk management and these difficulties are very difficult to overcome unless the allocation to these managers remains compounded to a very limited level.

Possible regulation of alternative investment vehicles by financial authorities could lead to market distortion and disastrous consequences for investors as well as for the very financial markets that the regulations aim to protect, by reducing efficiency of the most active and sophisticated participants. The effects of regulation in such an entrepreneurial environment has to be carefully assessed with the aim not only to protect investors from possible losses that result from allocating to risky hedge funds but also incentivating competition by creating more differentiated hedge funds as well as FOF with a higher upward potential.

\section{References and Notes}

1 Brown, S.J., Goetzmann, W.N. and Liang, B. (2003) 'Fees on Fees on Funds of Funds', NBER Working Paper No. 9464.

2 Baddepudi, R. (2007) 'Investing in Hedge Funds: A Long-term Proposition?', AIMA Journal, Spring 2007, to be found in: http://www.aima.org/uploads/ EurekaBaddepudi74.pdf.

3 Lintner, J. (1983) 'The Potential Role of Managed Commodity-Financial Futures Accounts (and/or funds) in Portfolios of Stocks and Bonds', Presentation at the Financial Analysts Federation.
4 Agarwal, V. and Naik, N.Y. (2001) 'Performance Evaluation of Hedge Funds with Option-Based and Buy-and-Hold Strategies', Working Paper, London Business School.

5 Fung, W. and Hsieh, D.A. (1998a) 'Price Trend Following Trading Strategies: Theory and Empirical Evidence', Working Paper, Foundation of Managed Derivatives Research, September.

6 Fung, W. and Hsieh, D.A. (1998b) 'A Risk Neutral Approach to Valuing Trend Following Trading Strategies', Working Paper, Duke University.

7 See Standard \& Poor's Fund of Hedge Funds rating process in http://www2.standardandpoors.com/spf/ pdf/products/HedgeFundRatingProcessFINAL.pdf.

8 Goetzmann, W., Ingersoll, J., Spiegel, M. and Welch, I. (2002) 'Sharpening Sharpe Ratios', NBER Working Paper No. W9116.

9 Sharpe, W. (1994) 'The Sharpe Ratio', Journal of Portfolio Management, Vol. 21, pp. 49-58.

10 Weisman, A. (2002) 'Informationless Investing and Hedge Fund Performance Measurement Bias', The Journal of Portfolio Management, Vol. 28, pp. 916-918.

11 Spurgin, R. (2001) 'How to Game your Sharpe Ratio', The Journal of Alternative Investments, Vol. 4, pp. $38-46$.

12 Lo, A. (2001) 'Risk Management for Hedge Funds: Introduction and Overview', Financial Analyst Journal, Vol. 58, pp. 16-33.

13 Brooks, C. and Kat, H. (2002) 'The Statistical Properties of Hedge Fund Index Returns and Their Implications for Investors', Journal of Alternative Investments, Vol. 5, No. 2, pp. 26-44.

14 Lo, A., Getmansky, M. and Makarov, I. (2004) 'An Econometric Analysis and Serial Correlation and Illiquidity in Hedge Fund Returns', Journal of Financial Economics, Vol. 74, No. 3, pp. 529-609.

15 Gregoriou, G. and Zhu, J. (2005) 'Evaluating Hedge Fund and CTA Performance, Data Envelopment Analysis Approach', John Wiley \& Sons, Inc, New York.

16 Fung, W., Hsieh, D.A, Naik, N.Y. and Ramadorai, T. (2006) 'Hedge Funds: Performance, Risk and Capital Formation', AFA 2007 Chicago Meetings Paper. Available at SSRN: http://ssrn.com/abstract $=778124$.

17 Bacmann, J-F, Jeanneret, P. and Scholz, S. (2006) 'Performance, Size, and New Opportunities in the Funds of Hedge Funds Industry', in Gregoriou, G. (ed.) 'Funds of Hedge Funds, Performance, Assessment, Diversification, and Statistical Properties', Elsevier Finance, Oxford, UK

18 Ineinchen, A. (2002) 'Do Funds of Hedge Funds Managers Add Value?' Journal of Wealth Management, Vol. 5, No. 1, pp. 8-25. 
19 Sharpe, W. (1988) 'Determining a Fund's Effective Asset Mix', Investment Management Review, Vol. 2, December, pp. 59-69.

20 Sharpe, W. (1992) 'Asset Management: Management Style and Performance Measurement', Journal of Portfolio Management, Vol. 18, No. 2, pp. 7-19.

21 Schwindler, O. and Oehler, A. (2006) 'Style Analysis of Funds of Hedge Funds: Measurement of Asset Allocation and Style Drift', in Gregoriou, G. (ed.) 'Funds of Hedge Funds, Performance, Assessment, Diversification, and Statistical Properties', Elsevier Finance, Oxford, UK.

22 Rockefellar, R.T. and Uryasev, S. (2000) 'Optimization of Conditional Value-at-Risk', Journal of Risk, Vol. 2, pp. 21-41.

23 Rockefellar, R.T. and Uryasev, S. (2001) 'Conditional Value-at-Risk for General Loss Distributions', Research Report 2001-5, ISE Department, University of Florida.

24 Favre, L. and Galeano, J.A. (2002) 'Mean-Modified Value-at-Risk with Hedge Funds', Journal of Alternative Investments, Vol. 5, No. 2, pp. 21-25.
25 Gregoriou, G. and Gueye, J.P. (2004) 'Risk-Adjusted Performance of Funds of Hedge Funds Using Modified Sharpe Ratio', Journal of Wealth Management, Vol. 6, No. 3, pp. 77-83.

26 Ross, L. (2002) 'Risk Exposure and Hedge Funds', Russell Research Commentary, Tacoma, WA.

27 Lhabitant, F.S. and De Piante Vicin, M.L. (2004) 'Finding the Sweet Spot of Hedge Fund Diversification', Working Paper, EDHEC Risk and Asset Management Research Centre, Nice, France.

28 Lhabitant, F.S. and Laporte, N. (2006) 'Funds of Funds of Hedge Funds: Welcome to Diworsification', in Gregoriou, G. (ed.) 'Funds of Hedge Funds, Performance, Assessment, Diversification, and Statistical Properties', Elsevier Finance, Oxford, UK.

29 Jorion, P. (2007) 'Risk Management for Hedge Funds with Position Information', Journal of Portfolio Management, forthcoming.

30 Gregoriou, G. (2003) 'The Mortality of Funds of Hedge Funds', Journal of Wealth Management, Vol. 6, No. 1, pp. $42-53$. 